\title{
CARACTERÍSTICAS DEL PERIODISMO LITERARIO DIGITAL EN ARGENTINA
}

\section{Characteristics of Digital Literary Journalism in Argentina}

\section{Características do jornalismo literário digital na Argentina}

Celina Nora Laura Salvatierra, Universidad Nacional de la Patagonia San Juan Bosco (Argentina)

celinanlsalvatierra@gmail.com

\section{Recibido: 17 de septiembre de 2019}

Aprobado: 11 de mayo de 2020

Fecha de prepublicación: 11 de diciembre de 2020

\section{RESUMEN}

Este artículo actualiza los sentidos que asume el periodismo literario digital argentino. En particular quisimos caracterizar los modos de organización y producción, y para eso seleccionamos un período que consideramos clave, en el que se crearon nuevas publicaciones o migraron al soporte digital (2012-2016). En relación con lo anterior, se realizaron entrevistas en profundidad con editores y se analizaron más de 150 textos de nueve revistas que trabajaron el macrogénero narrativo como parte de su estilo editorial. Los resultados permiten conocer los sentidos que se atribuyen a esta práctica periodística; identificar las lógicas del proceso de producción y aquellas estrategias que hacen referencia a lectores y lectoras representados/as.

Palabras clave: periodismo literario digital; Argentina; periodismo narrativo; soporte digital; revistas digitales. 


\section{ABSTRACT}

In this article, the meanings attributed by the digital literary journalism in Argentina are shown. In general, we aimed at characterizing the forms of organization and production. For such purposes, we have selected a key period wherein new publications were created or migrated to digital platforms (2012-2016). In relation to the foregoing, thorough interviews were conducted with editors and more than 150 texts from 9 magazines that dealt with the macrogenre as part of their editorial style were analyzed. The results reveal the meanings attributed to journalistic practice; to identify the logics of the production process and those strategies that make reference to the readership being represented.

Keywords: Digital literary journalism; Argentina; narrative journalism; digital platforms; digital magazines.

\section{RESUMO}

Este artigo dá conta dos sentidos assumidos pelo jornalismo literário digital argentino. De uma forma geral, pretendíamos caracterizar os modos de organização e produção e, para isso, selecionamos um período que consideramos fundamental, em que novas publicações foram criadas ou migraram para o meio digital (2012-2016). Em relação ao exposto, foram realizadas entrevistas em profundidade com editores e analisados mais de 150 textos de nove jornais que trabalharam no macrogênero como parte de seu estilo editorial. Os resultados permitem conhecer os significados atribuídos a essa prática jornalística; identificar as lógicas do processo de produção e as estratégias que fazem referência aos leitores representados.

Palavras-chave: jornalismo literário digital; Argentina; jornalismo narrativo; plataformas digitais; revistas digitais.

El periodismo literario en Argentina fue adaptándose al soporte digital progresivamente, en una acción que fue caracterizada por sus protagonistas como un hacer de "prueba y error". Fuentes secundarias ${ }^{1}$ dan cuenta de que el surgimiento de revistas digitales en el período 2012-2016 fue significativo tanto por la creación de nuevos proyectos como también por la migración del papel al soporte on line.

1 Empleamos, entre otras fuentes, los censos de la Asociación de Revistas Culturales de Argentina (AReCIA). Sitio web: http://revistasculturales.org/ 


\section{DISERTACIONES}

ESTUDIOS

Los desafios del periodismo narrativo

ISSN: 1856-9536

Doi: https://doi.org/10.12804/revistas.urosario.edu.co/disertaciones/a.8246

Volumen 14, Número 1 / Enero-junio 2021

Versión PDF para imprimir desde

http://revistas.urosario.edu.co/index.php/disertaciones

En esos mismos años, el contexto político, económico y mediático fue crucial para comprender esta actividad. A pesar de que no hubo políticas de respaldo al periodismo de segunda lectura, desde el sector se menciona entre las causas por las cuales era imprescindible hacer una revista a la necesidad de contar con una propia voz, una iniciativa que reivindicara a las prácticas periodísticas y que diferenciara a estos emprendimientos de las empresas tradicionales y generalistas que abarcan buena parte del mapa comunicacional en las distintas regiones del país. Se buscó, entonces, un periodismo que sentara posición en contraste con otro que redujo el uso de fuentes y que explotó un formato de noticia con menor cantidad de voces.

En relación con lo anterior, el periodismo literario basa su financiamiento en múltiples estrategias combinadas, entre las que aparecen el cooperativismo y la asociatividad con organizaciones estatales (mayormente universidades) y de la sociedad civil, suscripciones, venta de anuarios, oferta de talleres y aportes voluntarios. Pese a esta diferencia sustancial en lo que hace a recursos para su financiamiento, el resultado es un producto mediático de mayor calidad que se ofrece de forma diferenciada desde el formato magazine y que busca fidelizar lectores para crear comunidad.

\section{Qué es el periodismo literario digital}

Cuando hablamos de periodismo literario digital nos referimos al macrogénero que emplea recursos expresivos propios de la literatura para contar sus historias en torno a diversos temas de interés y no exclusivamente al periodismo cultural. También va más allá de la crónica y alcanza otros subgéneros como el perfil y la entrevista, el ensayo epistolar, el informe de investigación, el ensayo informativo, el documental web. Hablamos de una práctica que articula estrategias periodísticas para conformar un estilo que demanda mayor tiempo de reporteo y que elabora un temario investigativo e interpretativo de los temas de agenda, como producto diferenciado. Dicho temario ofrece como señas particulares herramientas de interpretación de tópicos que están siendo discutidos en distintos ámbitos. Junto con esto pone a disposición otros modos de presentar los datos que ya se conocen o temas no cubiertos relacionados con comunidades on line, como género y sexualidad, violencia institucional, movimiento $\mathrm{LGBTIQ}^{+}$, medicina alternativa y bienestar, políticas culturales y denuncias de casos de corrupción e impunidad ejercidas en los ámbitos político estatal y/o partidario, empresarial, sindical y eclesiástico.

Incluimos dentro de nuestra muestra textos de las revistas Anfibia ${ }^{2}$ (de la Ciudad Autónoma de Buenos Aires), Último Round ${ }^{3}$ (provincia de Buenos Aires), Escritura Crónica (provincia de Buenos Aires o también llamado 'conurbano bonaerense'), Tucumán Zeta ${ }^{5}$ (Tucumán), Telaraña Digital ${ }^{6}$ (Paraná, Entre Ríos), Deodoro ${ }^{7}$ (Córdoba), Islandia ${ }^{8}$ (Córdoba), Ajo ${ }^{9}$ (Mar del Plata, provincia de Buenos Aires) y Big Sur ${ }^{10}$ (Chubut-Patagonia).

\footnotetext{
2 http://revistaanfibia.com/

3 https://revistaultimoround.com.ar

4 http://www.escrituracronica.com

5 http://tucumanzeta.com

6 http://xn--telaraadigital-vnb.com.ar

7 http://deodoro.unc.edu.ar

8 http://www.islandia.com.ar

9 http://www.revistaajo.com.ar/

10 La revista dejó de estar disponible on line.
} 


\section{DISERTACIONES}

ESTUDIOS

Los desafios del periodismo narrativo

ISSN: 1856-9536

Doi: https://doi.org/10.12804/revistas.urosario.edu.co/disertaciones/a.8246

Volumen 14, Número 1 / Enero-junio 2021

Versión PDF para imprimir desde

http://revistas.urosario.edu.co/index.php/disertaciones

El criterio inicial para la selección de las publicaciones fue que hubiese piezas textuales periodísticas en sus páginas web que emplearan recursos literarios y que dicho estilo alcanzara a algunos textos y secciones o a la publicación completa. Además, se consideró que dichas producciones se hiciesen desde distintas regiones de Argentina, teniendo en cuenta que no todos estos emprendimientos tienen las mismas posibilidades asociativas, ya que hay condiciones desiguales para aquellos que se ubican en localidades y provincias más alejadas de los grandes centros urbanos. Los ingresos de la mayoría de los medios en el interior del país provienen de la publicidad oficial.

Un tercer criterio tuvo que ver con la viabilidad de acceso a los editores y editoras de las páginas elegidas a través de una comunicación mediada por distintas plataformas, de modo tal de lograr su atención y agilizar las entrevistas en profundidad. De esa forma se apuntó a dialogar en momentos en los que cada periodista pudiese estar tranquilo o tranquila, para que se sintiera libre de comentar, objetar y explayarse lo suficiente. Esta modalidad virtual se complementó con instancias presenciales en algunos casos, de las que una se realizó al secretario de redacción de Anfibia y otra a un referente de AReCIA.

\section{Antecedentes teóricos}

Las referencias teóricas que revisamos al inicio de nuestra investigación estuvieron vinculadas a las discusiones en torno a la definición de los géneros narrativos y a su puesta en funcionamiento. Bajo tal propósito la lectura obligada fue la obra de Chillón (1999, 2014), quien articula teoría literaria, géneros periodísticos y teoría de la comunicación. En el primer texto, donde inaugura su propuesta sobre las relaciones "promiscuas" entre literatura y periodismo, Chillón (1999) sostiene que la crónica es "un modo de ver al mundo, aunque basada en la relación lenguaje-conocimiento" (p. 70). Para este autor, además de ser producción de conocimiento, los géneros periodísticos son convenciones discursivas sometidas a cambio permanente en virtud de transformaciones históricas y de las formas culturales de producción y consumo (Chillón, 1999, p. 27). Dichos acuerdos sociales y temporales dialogan entonces con las distintas dimensiones que asumen esos contextos: histórica, económica, social, cultural y tecnológica. Un ejemplo de cambio en las dimensiones tecnológica y económica es la migración del soporte de papel al digital, que, a la vez, habilitó nuevas posibilidades culturales o de 'contaminación' entre géneros y lenguajes, como las producciones transmedia, los documentales de corta duración producidos para la web o las docuseries. Estas ideas son trabajadas tanto por Herrscher (2016) como por el mismo Chillón (2014), quienes analizan de forma puntual esas potencialidades de los géneros narrativos. Precisamente, otras autoras - como Montes (2013), Papalini (2011) y Larrondo (2010) - reconocen al menos dos elementos que aún distinguen los géneros narrativos: uno que reúne aspectos convencionales y otro aún abierto, más abstracto pero igualmente operacionalizable, que remite a la necesidad de indagar de manera inductiva y creativa.

Otro aspecto que emerge de forma recurrente en las definiciones de crónica y de entrevista tiene que ver además con la posibilidad de compartir con los lectores y lectoras la experiencia del cronista mediante la autorreferencialidad. Esto nos remitió a Rodolfo Walsh en relación con el manejo de recursos de escritura que hoy se siguen conservando ante la intención de sostener la tensión en el texto, que, en el caso de Walsh, era una destreza que estaba directamente asociada a su entrenamiento como escritor de cuentos policiales. Esa característica de los 


\section{DISERTACIONES}

ESTUDIOS

Los desafíos del periodismo narrativo

ISSN: $1856-9536$

Doi: https://doi.org/10.12804/revistas.urosario.edu.co/disertaciones/a.8246

Volumen 14, Número 1 / Enero-junio 2021

Versión PDF para imprimir desde

http://revistas.urosario.edu.co/index.php/disertaciones

géneros narrativos se combina en la actualidad con nuevas coordenadas del soporte digital, como, por ejemplo, el hecho de tener que presentar el conflicto en las primeras líneas, o escribir teniendo en cuenta una determinada secuencialidad necesaria para la lectura en dispositivos móviles.

Por otra parte, el temario es un punto de encuentro entre el contexto, el medio y sus lectores/as. Fontcuberta y Borrat (2006) señalan que la categoría articula la demanda de información del público, el interés de dar a conocer ciertos temas y una comunicación estratégica (Fontcuberta \& Borrat, 2006, p. 58). Dicha comunicación estratégica se traduce en la actualidad en la necesidad de alcanzar y fidelizar a los lectores y lectoras que se mueven en un mar de información y que tienen a disposición múltiples posibilidades de consumo en la web. Por ejemplo, una de las ideas que prima entre el periodismo de segunda lectura es que una de las demandas específicas de tiempos de posverdad es la de la calidad periodística. Al respecto, Luchessi (2013) indica que, en efecto, hay una disminución de la calidad periodística, dado que emerge una nueva racionalidad en la recepción que interpela la producción y el acceso a fuentes. Así sostiene que los lectores actuales tienen maneras de verificación, situación que a su entender incide de forma directa en la calidad de los datos que circulan y trastoca el organigrama de la organización periodística con nuevas funciones. Siguiendo tanto a Luchessi (2013) como a Rincón (2013), la crítica situación de los contenidos, más que nada aquellos que están en la web pero que son una copia de productos comunicacionales tradicionales - de revistas, diarios, tv o radio-, se puede no solo relacionar, sino entender, a partir del hecho de que los lectores aprendieron a desconfiar de todos los productos comunicacionales que los interpelan. Ante este panorama, investigadores tales como Bernardi (2016) sostienen que las teorías clásicas del campo disciplinar de la comunicación deben actualizarse a la luz de estas demandas. Bernardi (2016) -quien se interesa, por ejemplo, por las particularidades de la labor periodística en diarios regionales del sur argentino y se pregunta por el perfil profesional de quienes integran los equipos- explica que en la actualidad "no hay un modelo a seguir en la producción", dado que este ámbito de los medios generalistas digitales todavía "está en desarrollo" (p. 71). De esta forma la producción no tiene recetas, sino patrones cíclicos de prueba y error, tal como encontramos en otro tipo de medios, como los de segunda lectura. En lo que respecta a la calidad del periodismo, se sabe que una forma de operacionalizar dicha categoría es a través del conteo de la cantidad de fuentes empleadas en los textos. Si bien en nuestra muestra detectamos que en los textos cambia el número de fuentes de las que se vale el narrador de acuerdo con el tipo de subgénero narrativo empleado, lo cierto es que las revistas estudiadas utilizaron un promedio de más de tres por texto, en contraposición a lo que ocurre con otros medios digitales e impresos y noticieros televisivos, donde la tendencia fue de una fuente por nota.

En un artículo para la revista Letra P, Zunino (2018) hace referencia al estudio del Observatorio de Medios, Democracia y Ciudadanía sobre ocho de los principales medios generalistas digitales de Argentina (MDz, Uno, La Capital, Los Andes, La Voz, Página/12, Clarín y La Nación). Allí revela que la cantidad de fuentes citadas -durante los años 2017 y 2018- corresponde a 1,43 por nota, situación que se aleja de las tres fuentes indicadas por los manuales de periodismo como garantía de calidad informativa.

Con respecto a lo anterior, el $57,2 \%$ de esas fuentes eran oficiales, y entre ellas se destacaban los poderes del Estado y funcionarios de gobierno, seguidas por otros actores sociales con poder político o económico, como sindicatos y empresas. En contraposición, los ciudadanos y organizaciones sociales lograban tener voz a partir de casos individuales identificados como "principalmente policiales", o al ser "testigos o víctimas". Si bien esos porcentajes cambian en contextos de crisis sociales y de otra índole, nos interesó especialmente considerar estos 


\section{DISERTACIONES}

ESTUDIOS

Los desafíos del periodismo narrativo

ISSN: 1856-9536

Doi: https://doi.org/10.12804/revistas.urosario.edu.co/disertaciones/a.8246

Volumen 14, Número 1 / Enero-junio 2021

Versión PDF para imprimir desde

http://revistas.urosario.edu.co/index.php/disertaciones

abordajes para reflexionar en torno a otro tipo de medios. Pellegrini y otros (2011) hicieron referencia a la misma tendencia, aunque en los diarios generalistas impresos de Chile, Perú, Colombia y Argentina. Allí el empleo de fuentes profesionales o expertas y las testimoniales quedó supeditado a un segundo o tercer plano. En los cuatro países, los niveles de relevancia -índice que hace referencia a la cantidad de fuentes empleadas - fueron similares y se ubicaron entre 2 y 2,5 e iban a la baja en 2009, al situarse en el rango de 2,1 y 2,2 fuentes por texto (Pellegrini et al., 2011, pp. 156-157). Si bien la prensa argentina y la peruana aparecieron con la cobertura de mayor relevancia (en torno a las 2,2 fuentes por nota), el escaso uso de otras voces se sostuvo y dicha situación se volvió transferible tanto a diarios de pequeñas localidades del interior en Argentina como a la prensa mundial.

Una práctica de producción similar se registró en otros productos comunicacionales del periodismo. La Defensoría del Público de Servicios de Comunicación Audiovisual en Argentina monitorea los noticieros televisivos y por su intermedio es posible corroborar que en el período 2013-2017 hubo un decrecimiento del tiempo promedio de duración de la noticia a nivel general, por lo que de manera relacionada se contó con menos posibilidades de incorporar fuentes a dichos relatos. En consecuencia, la relación fuente/noticia pasó del valor 1 entre 2013 y 2014 (1,12 y 1,02 fuentes por noticia) a una probabilidad mucho menor de empleo de otras voces además de la del periodista (es decir, de 0,98 y 0,82) entre 2015 y 2017.

Para Amado (2018), la situación daba cuenta de la crisis del periodismo en relación con "la poca importancia que se les da a los ciudadanos tanto como fuentes y protagonistas de las noticias en general, y como lectores de los diarios en particular" (p. 68). La misma autora afirma que "la mayoría de las noticias tienen fuente única, son mayormente personales (en el $63 \%$ de las noticias) antes que documentales", y que "los ciudadanos aparecen en una de cada diez noticias, lo mismo que sus organizaciones". A la vez, habla de un periodismo sin base fáctica y cargado de denuncias atribuidas a terceros. "El periodismo de opinión es altamente valorado [...], sin embargo, los indicadores que ponen al periodismo de intervención como el rol que más aparece en los diarios no necesariamente replican el estilo comprometido de expresión de opiniones y propuestas, o de un periodismo en primera persona" (Amado, 2018, pp. 68 y 69).

\section{Diseño metodológico}

Nuestro diseño cualitativo tuvo como técnicas de recolección de datos una decena de entrevistas semiestructuradas y el análisis de más de 150 textos y de capturas del diseño de las páginas web. Mediante el programa Atlas.ti, se empleó el método de comparación constante y la codificación por etapas (abierta, axial y selectiva). También se efectuó un conteo de la extensión de los textos de las muestras de cada revista y se codificaron los comentarios hechos al pie de los artículos como forma de observar la repercusión e interactividad en textos considerados centrales para los mismos editores.

Si bien el diseño se basa en la teoría fundamentada, tuvo adaptaciones de manera posterior en la necesidad de reintegrar entre sí los datos obtenidos para la caracterización del fenómeno en cuestión. Precisamente, apelamos a la 'sensibilidad teórica' que promueve el mismo método y ejercitamos una vigilancia que consistió en 'dejar hablar a los datos', sumando otros que nos resultaron de utilidad. ${ }^{11}$

11 Para trabajar este método, recomendamos la lectura de Charmaz (2013). 


\section{DISERTACIONES}

ESTUDIOS

Los desafios del periodismo narrativo

ISSN: 1856-9536

Doi: https://doi.org/10.12804/revistas.urosario.edu.co/disertaciones/a.8246

Volumen 14, Número 1 / Enero-junio 2021

Versión PDF para imprimir desde

http://revistas.urosario.edu.co/index.php/disertaciones

En las entrevistas semiestructuradas se propusieron los siguientes ítems: motivos de creación de los proyectos, objetivos, descripción de los contextos, apuesta a los géneros narrativos; estructura organizacional (roles, tareas, jerarquías, modalidad de toma de decisiones, vínculos, tiempos de producción y publicación, frecuencia de publicación); canales comunicativos, espacios de trabajo, modos de encuentro y lugares; decisiones en torno al diseño, a la distribución de los textos en redes sociales, representaciones del/a lector/a, formas participativas implementadas o desestimadas (criterios para la gestión de comentarios); y otros aspectos que quedaron a criterio de la/los entrevistados. En el mismo instrumento, se incluyeron a modo de preguntas si era confiable la medición de visitas a las páginas de las revistas, aspectos del financiamiento y aquellas actividades de conocimiento de los seguidores de las publicaciones.

Los hallazgos en las entrevistas se asocian a experiencias en común de los/la periodista/s tras ahondar en sus trayectorias biográficas (describieron que habían trabajado o que aún desempeñaban tareas en redacciones generalistas tradicionales) y con su perspectiva crítica y reflexiva en torno a lo realizado por los medios digitales de actualización permanente.

\section{Resultados}

Las categorías principales resultantes de las distintas etapas de codificación son aquellas que, relacionadas, permiten caracterizar la naturaleza de la práctica actual del periodismo literario, así como también la representación del lector en la instancia de producción. En este último lineamiento, se incluyen las estrategias narrativas que se emplean para captar y mantener la atención del lector, como, por ejemplo, los recursos de escritura a los que se suman otros de diseño web y secuencialidad, dado que los textos son leídos en pantallas. En virtud de lo anterior, parte del análisis consistió en establecer esas relaciones conceptuales fuertes entre categorías más importantes, y otras entre categorías y conceptos, y de conceptos entre sí, como también identificar los sentidos de dichas relaciones.

\section{El periodismo digital y su contexto}

Primer hallazgo: el periodismo literario digital encuentra su identidad en la diferenciación. No obstante, no lo hace en contraste con revistas o páginas de periodismo narrativo o literario, sino que busca distinguirse entre otros medios regionales y nacionales generalistas, tradicionales y hegemónicos.

Las modalidades en las que se construye ese valor se dan a partir del empleo de otras formas de contar las historias, es decir, a través de recursos narrativos, pero también valiéndose de cierta autonomía, propia de redacciones con mesas chicas de editores-fundadores que cuentan con decenas de colaboradores. Otro elemento es el estilo magazine de publicación semanal, la oferta de contenido propio por secciones con la posibilidad de publicar al ritmo de una actualidad permanente y prolongada, ${ }^{12}$ aunque la citada flexibilidad editorial de estos proyectos también les permite hacer coberturas especiales o 'urgentes'.

12 Rost (2004) define a la actualidad prolongada como aquella que comprende los hechos con elementos que se prolongan en el tiempo y que son abordados como un proceso; mientras que la actualidad permanente son los hechos que por su importancia o características específicas siempre interesan al público. Un tema 


\section{DISERTACIONES}

ESTUDIOS

Los desafios del periodismo narrativo

ISSN: 1856-9536

Doi: https://doi.org/10.12804/revistas.urosario.edu.co/disertaciones/a.8246

Volumen 14, Número 1 / Enero-junio 2021

Versión PDF para imprimir desde

http://revistas.urosario.edu.co/index.php/disertaciones

(Editor de Tucumán Zeta): Te diría que toda la edición urgente del saqueo, de 2013, toda esa edición marcó un antes y un después. ${ }^{13}$ Había mucha avidez por informarse por lo que estaba pasando, toda la gente estaba encerrada en sus casas recibiendo mensajes alarmantes por WhatsApp: que ya llegaban los ladrones, había mucha desinformación. Estaban ocurriendo muchas muertes más de las que contaba La Gaceta - porque nos enteramos (Tucumán es muy chico), yo tenía un amigo en el hospital central de Tucumán, el Hospital Padilla, y me decía que habían muerto cinco pibes en enfrentamientos con los vecinos y La Gaceta te decía que había habido solamente un muerto-. Entonces, ¿cómo puede ser? Ahí tuvimos el valor de contar eso, que había más muertos que los muertos oficiales, pero no solo decirlo, sino con nombre y apellido, y contar por qué no estaba en las listas oficiales. En el medio de todo, muchos hasta ideológicamente se abrazaron a Tucumán Zeta, porque decían acá hay un medio que está contando otra parte de la realidad, ¿no? Ahí hubo un antes y un después.

Si ocurren situaciones críticas que requieren de denuncia, la frecuencia de publicación cambia. Esta versatilidad da cuenta de la necesidad de diferenciarse desde la línea editorial. A eso se añade que los textos narrativos se proponen como ordenadores, como arquitecturas de interpretación de hechos del presente que pueden tener conexión -o no- con otros del pasado. De esta forma, la capacidad de ofrecer historias y de enmarcarlas a partir de otras que ya son conocidas es una característica de esta puesta en valor.

\section{El periodismo literario digital y sus estrategias para atraer lectores/as}

Parte del atractivo de una revista digital es el universo de temas que articula (temario), por lo que la capacidad de atraer lectores y lectoras no se agota en el empleo de recursos de escritura, sino que explora diversidad de posibilidades dentro de la misma publicación y en distintos entornos de lectura. A lo anterior se suman acciones de gestión de la información desde el diseño; en redes sociales y entre comunidades virtuales, lo que se complementa con estrategias presenciales, tales como talleres, publicación de anuarios y/o la realización de distintas actividades culturales.

Antes de referirnos puntualmente a las estrategias de escritura, debemos pensar primero en términos de representaciones en torno a la lectura digital de generaciones de periodistas-editores/as que promedian los 30 años, teniendo en cuenta que se iniciaron o crecieron en el contexto de redacciones no digitales. De esta manera se detecta una combinación de recursos tradicionales de la crónica y otros géneros con estos nuevos aprendizajes adquiridos mediante la labor editorial.

que puede ser objeto de tratamiento de la actualidad permanente es, por ejemplo, la violencia de género. El enfoque aquí es el del gran reportaje, con una redacción y presentación más elaborada y con una extensión mayor a las noticias que caracterizan a la actualidad reciente. Finalmente, para el mismo autor, la actualidad reciente incluye los hechos que han sucedido o han sido descubiertos en el transcurso del día.

$13 \mathrm{El}$ entrevistado hace referencia a una serie de huelgas policiales en reclamo de mejoras salariales que afectaron a distintas provincias argentinas y que en Tucumán derivaron en disturbios, toma de edificios públicos y saqueos a comerciantes, con un resultado de decenas de personas fallecidas al promediar diciembre de 2013. 


\section{DISERTACIONES}

ESTUDIOS

Los desafios del periodismo narrativo

ISSN: $1856-9536$

Doi: https://doi.org/10.12804/revistas.urosario.edu.co/disertaciones/a.8246

Volumen 14, Número 1 / Enero-junio 2021

Versión PDF para imprimir desde

http://revistas.urosario.edu.co/index.php/disertaciones

Un componente asociado a la tradición de la escritura del periodismo literario es el estilo de los títulos, que tienen como requisito resultar atractivos o creativos e interpelar a quien los lee. La referencialidad en los modos de titular no es tan explícita en estos casos como en los del periodismo generalista, sino que sugiere y muchas veces da por sentado que la información principal sobre la que el artículo ahondará ya se conoce. De esta forma, el título también apela a la originalidad, más allá de que la información básica se haya difundido o no.

En los casos analizados tampoco rige de modo tan estricto la fórmula en la que en los títulos debe ir indefectiblemente un verbo, sino que muchas veces hay variaciones y los encontramos con una palabra o dos ("Ficciones", "Galleros", "Volver”, "Mundo porno", "Los fachos”), sin hacer referencia específica al sujeto de la oración ("Fuiste un lujo", "El estilo en la mirada", "Buenos muchachos") o mencionándolo de manera tal que genera intriga ("Cuando Walsh solo escribía”, "Honrarás a Talese”, “El rompecabezas Nisman”, “A pedido de Benetton”, "Atilio, el todólogo”), haciendo también referencia a lugares geográficos y simbólicos ("La china invisible", "En el corazón del monstruo", "Un pueblo de doce personas y una cancha de fútbol"). En cierta forma, pareciera que el periodismo literario sigue teniendo mayor margen de creatividad para titular si volvemos a pensarlo en relación con otras propuestas mediáticas periodísticas.

El título además busca ser transgresor o dar cuenta de aspectos nuevos de un tema ya conocido ("Sé lo que hicieron en el diario El Atlántico", "Otro sacrificio para el dios agroindustrial”), puede ser una interrogación ("¿Coger no es amor?”, “¿Quién dijo que no hay negros en Rumencó?”, “Soy cuartetero, ¿y qué?”), hacer alusión al tema de la crónica o de la entrevista dejando lugar también a las frases destacadas de los entrevistados ("Macri es la nada, loco") o a frases conocidas o desconocidas de personalidades ("Derrote el terror").

Otras estrategias de escritura y composición de los textos son aquellas que ofrecen explicaciones o modos de mantener al lector centrado en la historia: entre ellas contamos a los raccontos (narraciones preactivas) y la explicación de las tramas y conflictos.

Contrariamente a lo que podría pensarse, el hecho de que estas publicaciones apuesten a textos más extensos no parece ser un impedimento para la lectura, aunque algunos editores más interesados en un/a lector/a más joven y ocupado en múltiples actividades elaboraron criterios de extensión máxima.

En general se pide que las historias tengan suficiente desarrollo y un final acorde, aunque en algunas revistas, como Ajo, el periodismo de largo formato se constituyó como marca (su eslogan fue precisamente "periodismo de largo aliento"), por lo que en ese aspecto la crónica y los informes narrativos volvieron a su naturaleza inmersiva heredada de los textos tradicionales. Pero, a pesar de esas características, encontramos en otras revistas, como Escritura Crónica, ideas que se asociaron a nuevas tendencias de lectura en la web, por lo que el criterio apuntó a escribir textos más cortos.

(Editora Escritura Crónica): Sabemos que hoy en día, sobre todo la gente de las ciudades, tiene muchas actividades pero a la vez tiene sus tiempos muertos, que sé yo, viajando, y tenés siempre un dispositivo móvil a mano, tenés el celular, entonces como tratando de adaptarnos a esa realidad es que dijimos que sean textos cortos. Eso no quiere decir que igual no sean textos con mucho laburo, porque no es que porque sean cortos se hacen en 10 minutos; la verdad es que nos llevan un montón de tiempo.

Al comparar las publicaciones entre sí descubrimos una variabilidad importante de entre 10 y 200 párrafos, por ejemplo. Esto permite identificar que en el soporte digital escribir más no tiene las mismas implicancias o costos que en el papel, aunque, como vimos, para ciertas revistas como Escritura Crónica, los límites están dados 


\section{DISERTACIONES}

ESTUDIOS

Los desafios del periodismo narrativo

ISSN: 1856-9536

Doi: https://doi.org/10.12804/revistas.urosario.edu.co/disertaciones/a.8246

Volumen 14, Número 1 / Enero-junio 2021

Versión PDF para imprimir desde

http://revistas.urosario.edu.co/index.php/disertaciones

por lo que se sabe en torno a la capacidad de concentración y de lectura continua de sus lectores. Entre todas las publicaciones, la que ofreció textos más largos fue Anfibia (de hasta 8500 palabras), ${ }^{14}$ mientras que Escritura Crónica ocupó un quinto lugar de un orden decreciente (con un texto de hasta 3800 palabras), ${ }^{15}$ habiendo otras cuatro publicaciones con trabajos de extensión similar y menor.

En lo que hace al diseño, las separaciones dentro de los mismos artículos tienen un uso estratégico (a modo de narración por escenas) que facilita la lectura, dado que el lector no es consciente del paso de las páginas cuando lee en pantalla de teléfono, por lo que la secuencialidad es otra estrategia que además traza marcas de escritura, ya que determina apertura y cierre de las subtramas dentro de las historias.

En general, otros recursos de diseño (para atraer al lector/a) en las revistas son frases destacadas, fotografías, ilustración y collages de gran tamaño, sumando galerías -en algunos casos, como los de Tucumán Zeta, Anfibia e Islandia, hay secciones o trabajos específicos destinados a fotorreportajes y/o ensayos fotográficos- y videos.

En la mayoría de los casos, los videos se emplearon como complemento de las fotografías e ilustraciones que acompañaron a los textos. Precisamente, la palabra fue el principal recurso que asumió la función narrativa en las historias. Si bien se utilizaron fotos de gran tamaño para los slides de presentación que se deslizan en pantalla, las más recurrentes en los artículos fueron las de tamaño medio (que compartieron el espacio en pantalla con el texto en los diseños responsivos), y la cantidad siempre dependió de la extensión del artículo, ya que las fotos son otra forma de establecer separaciones que contribuyen al descanso en la lectura.

Como vimos, hay en la muestra analizada una combinación de recursos tradicionales con otros aprendidos. Son ejemplo de lo heredado las descripciones de situaciones, paisajes y de personajes, narración por escenas, citas comentadas, diálogos reproducidos, empleo de objetos referenciales, autorreferencialidad, el planteamiento de un conflicto y la explicación de su singularidad. Esto último se complementa con otras estrategias producto del aprendizaje colectivo, por ejemplo, el hecho de que en el soporte digital el conflicto tenga que aparecer relativamente pronto; son necesarios más raccontos y explicaciones de tramas, secuencialidades que obligan a hacer pausas, y también se apela a la puesta en escena de experiencias para emocionar al lector o lectora.

\section{Las mutaciones de la crónica y de otros subgéneros}

A lo largo del período estudiado, Tucumán Zeta buscó conservar la mayor cantidad de características de la crónica latinoamericana, mientras que Anfibia enunció su propia "teoría de la crónica" heredera del enfoque etnográfico, sumando lo que se llamó una ferviente "búsqueda del rigor periodístico" con elementos de conflicto y ritmo para atrapar al lector. Es interesante notar que Anfibia nació en sus primeros años más cercana a la crónica tradicional latinoamericana y que luego su estilo se volvió más ensayístico con textos que tuvieron rasgos de comunicación científica o una impronta más cercana a temas actualidad. En el caso de Último Round, la apuesta central se relacionó con el empleo de la entrevista narrativa como recurso de introducción de otras voces atractivas para el

14 Es ejemplo el artículo "Qué es el periodismo literario", que en realidad es un fragmento del libro Zona de obras de Leila Guerriero. Disponible en http://revistaanfibia.com/cronica/que-es-el-periodismo-literario/

15 "Un pueblo de doce personas y una cancha de fútbol". Disponible en http://www.escrituracronica.com/ cronicas/2014/10/2/un-pueblo-de-doce-personas-y-una-cancha-de-ftbol?rq=un\%20pueblo 


\section{DISERTACIONES}

ESTUDIOS

Los desafíos del periodismo narrativo

ISSN: $1856-9536$

Doi: https://doi.org/10.12804/revistas.urosario.edu.co/disertaciones/a.8246

Volumen 14, Número 1 / Enero-junio 2021

Versión PDF para imprimir desde

http://revistas.urosario.edu.co/index.php/disertaciones

lector; mientras que Telaraña Digital apostó mayormente a un tratamiento narrativo de historias que evocaron la memoria colectiva en pueblos y ciudades del norte de Argentina y a derechos humanos.

(Editor de Telaraña Digital): Desde el arranque la idea era que la revista se definiera más por el estilo que por los contenidos, o sea, el estilo del periodismo narrativo, aunque las inquietudes de todos los que hacíamos la revista eran básicamente similares y tenían que ver con derechos humanos, con los derechos de las mujeres, con la diversidad sexual y la cultura, y también nos interesaba sobre todo la innovación y hacer algo desestructurado, fuera de las estructuras normales del periodismo al que nosotros estamos acostumbrados a trabajar, que es el periodismo de diario. Queríamos jugar un poco con las herramientas propias de la literatura como se hace en el periodismo narrativo. Si bien en un principio la revista no fue planteada con la idea de que fuera con seis temáticas, fue decantando hacia ahí a tal punto de que cuando nosotros decidimos hacer el pasaje al formato digital ya directamente definimos secciones que son las que están ahora en la página, en el portal, que son: memoria, género, política, justicia, trabajadores y vida cotidiana.

(Editor de Último Round): Es cierto que nosotros nos llevamos muy bien con la entrevista, creemos que es central y coincide con el tipo de publicación militante que nosotros podemos construir. Coincide con eso. Después hay cosas más ligadas a la poesía, al cuento, pero la revista está más ligada a la entrevista que a la poesía si se quiere.

\section{A modo de puente entre emisores y receptores: un temario posible}

El temario cumple con distintos propósitos. En principio pone en discusión problemáticas que los editores reconocen como de interés para sí mismos y en teoría para sus lectores según su representación. El tratamiento de los temas - desde el género narrativo- no hace referencia a una supuesta neutralidad, sino que se pone de manifiesto desde la autorreferencialidad, las percepciones y puntos de vista marcados del narrador, en la búsqueda de una voz que no pretende ser 'objetiva', sino 'equilibrada'. Ese temario presenta historias relacionadas con feminismos, masculinidades, violencia de género, aborto y sexualidad, arte y políticas culturales, críticas y reflexiones sobre periodismo, medios y políticas de comunicación, medicina alternativa y bienestar, temas de denuncia de violencia institucional, policial, situación carcelaria, marginalidad, políticas y participación sindical, estudiantil, universitaria, políticas del cuerpo, pornografía, fertilidad, prostitución, poderes e impunidad política, empresarial, sindical y eclesiástica, derechos humanos, identidades, colectivo LGBTTTIQ+, historia y dictadura, políticas de la imagen presidencial, empleo y pobreza.

Estos temas se conjugan en los géneros narrativos digitales con periodismo de investigación y/o de denuncia. Precisamente, en el tratamiento de los temas hemos encontrado rasgos que hacen directa referencia a la calidad informativa, como el uso variado de fuentes especializadas, profesionales, documentales, testimoniales y también estadísticas.

En lo que hace a un factor como la hipertextualidad, el relevamiento de links en los artículos del corpus permitió identificar que sus usos apuntaron a ofrecer fuentes documentales complementarias al texto central: videos, páginas y documentos oficiales disponibles en línea. 


\section{DISERTACIONES}

ESTUDIOS

Los desafíos del periodismo narrativo

ISSN: 1856-9536

Doi: https://doi.org/10.12804/revistas.urosario.edu.co/disertaciones/a.8246

Volumen 14, Número 1 / Enero-junio 2021

Versión PDF para imprimir desde

http://revistas.urosario.edu.co/index.php/disertaciones

Al hablar de la naturaleza del temario nos referimos tanto a acuerdos colectivos como a autonomía. Si bien es cierto que los editores pueden pedir determinadas coberturas, también los colaboradores se sienten en libertad de ofrecer el tratamiento de historias que les resultan de interés. Los criterios de noticiabilidad en este caso son una combinación de ambos factores, siendo que son los y las editores/as quienes apelan a los valores identitarios y fundacionales dentro de estos proyectos. A veces, parte de estos valores se socializa a través del manual de estilo y otras veces se aprende como producto de la interacción presencial y virtualizada, pero también como hábito de escritura y de lectura de la misma publicación.

En esta construcción de sentido en torno al producto, aparece también el/la lector/a, como una figura que tiene determinados intereses y expectativas que se deben cubrir. De acuerdo con nuestro abordaje, podemos decir que esta representación se asocia tanto con el temario (que apela a lo local-regional, a la empatía y a otras configuraciones de interés) como con los recursos de escritura y otros aspectos que derivan de esa relación, tales como la reivindicación de la calidad periodística.

Por todo esto, la categoría temario es una puesta en diálogo tanto con los contextos profesional, histórico-social, como también con las ideas subjetivas y colectivas que se tienen en torno a quienes prefieren este tipo de productos comunicacionales. La agenda de estos medios prioriza el contenido propio y cercano a los lectores y lectoras, y su modo de presentación responde a códigos compartidos con sujetos que aprendieron a desconfiar incluso de sus medios predilectos, ${ }^{16}$ quienes disfrutan de textos que tienen una posición ideológica expuesta, que apelan a la emotividad o empatía pero formulada desde la primera persona y que también atienden al presente y pasado compartidos en clave histórica.

Consideramos entonces que el temario permite indagar cómo se ajusta una propuesta periodística a las reacciones, intereses y competencias de los destinatarios/as, en un encuentro de intuición, de expectativas y aprendizajes.

\section{La representación del lector y la gestión de comentarios}

En lo que hace a la representación del lector, como aspecto de particular interés, la producción de periodismo literario digital hizo referencia a un/a destinatario/a 'joven' (en algunos casos casi adolescentes y en otros jóvenes-adultos) que no dispone de mucho tiempo para leer, aunque puede dedicar algunos minutos a un texto narrativo usando su celular en tiempos de traslados, de espera y también de rutina laboral. Dicho/a usuario/a no es necesariamente académico/a, aunque está interesado/a en conocer temas complejos (en términos de otros modos de tratamiento de una historia) pese a que su búsqueda no apunta a una experiencia inmersiva o estética como única prerrogativa, sino que además exige claves de interpretación de temáticas que hacen a su ciudadanía, a su lugar en el mundo.

16 En una entrevista en la que Anfibia publicó un fragmento de Pensar el periodismo (2016) de Sebastián Lacunza, Julio Blanck (Clarín) señalaba que en el caso argentino la desconfianza era el triunfo cultural del kirchnerismo sobre el periodismo profesional. Una versión más cercana a la gestión de la Lsca propone a la ley como disparador de ese cambio cultural en las audiencias. Blanck añadió -en el mismo contexto-que el diario generalista en el que se desempeñó no tenía "tiempo, ni método, ni recursos, ni siquiera el objetivo de contarla verdad. Nuestro objetivo es lo verosímil. El verosímil se puede trabajar aun en el ritmo del online". Disponible en: http://www.revistaanfibia.com/en-clarin-se-angosto-la-posibilidad-pensar-distinto/ 


\section{DISERTACIONES}

ESTUDIOS

Los desafios del periodismo narrativo

ISSN: 1856-9536

Doi: https://doi.org/10.12804/revistas.urosario.edu.co/disertaciones/a.8246

Volumen 14, Número 1 / Enero-junio 2021

Versión PDF para imprimir desde

http://revistas.urosario.edu.co/index.php/disertaciones

No obstante, si agrupamos otras manifestaciones dentro de la categoría 'lector/a', se habilitan más lecturas. Un aspecto que nos pareció interesante fue el hecho de que los contenidos que resultaron significativos para los editores, por la cantidad de visitas registradas y otros aspectos, no tuvieron - en el período estudiado- la suficiente gestión de comentarios que sirviera para, por ejemplo, la producción de nuevos materiales más participativos -o alguna exploración en ese sentido- que facilitara el conocimiento mutuo. ${ }^{17}$ Sobre el total de las 9 revistas, fue posible recuperar los comentarios de 7 de ellas, ya que en uno de los casos directamente no estuvieron habilitados y en otro solo se podía escribir a la publicación aunque no visibilizar interacciones previas.

A la vez, al relevar los comentarios notamos que los usuarios no quisieron opinar en todos los artículos, sino -más que nada - en aquellos que se vincularon a sus experiencias personales, ideológicas y/o al componente emotivo. Un caso singular fue el del ensayo epistolar "Fuiste un lujo", que hizo referencia al recambio presencial en 2015. Dicha pieza periodística ${ }^{18}$ resultó ser la más comentada, con 630 intervenciones que suscitaron decenas de conversaciones, una cifra que seguía creciendo a pesar del paso de los meses y de los años. Allí, los destinatarios - usuarios de Anfibia - aportaron datos, manifestaron identificación personal y emotividad, hicieron valoraciones tanto positivas como negativas, y en varios casos (cuyo análisis ameritaría otra investigación) contaron sus propias historias personales en relación con el tema central del ensayo. En sus expresiones, se dirigieron tanto al autor de este ensayo epistolar como a la figura pública a la que hizo alusión el relato, también a la publicación y en ocasiones incluso a la universidad (que brinda apoyo a la revista).

En relación con lo anterior, la paradoja de la relación entre publicaciones y sus lectores y lectoras "interactuantes" (que pueden ser conceptualizados como quienes en efecto leen parte o la totalidad de algún artículo y que además interactúan) no fue un tema poco explorado solamente por el periodismo literario sino que se constituyó como aspecto crítico de la mayoría de los medios digitales argentinos. Es interesante preguntarnos si las claves para comprender dicha posible tensión pueden estar vinculadas a los valores que se comparten desde la cultura profesional periodística aprendida en las redacciones y editoriales tradicionales, donde la figura del autor sigue teniendo peso a diferencia de lo que ocurre en otros entornos.

\section{Conclusiones}

El objetivo principal de este trabajo tuvo que ver con identificar los sentidos de la práctica periodística en soporte digital que emplea recursos de la literatura para contar sus historias. Es así como los rasgos del periodismo literario digital se presentan a través de relaciones conceptuales fuertes entre las categorías principales de este estudio (periodismo literario digital y el/la lector/a) y las demás subcategorías.

Desarrollamos aquí algunas de esas relaciones fuertes encontradas y mencionamos brevemente otras.

17 Es necesario especificar que Anfibia ha sido la publicación que más pasos dio en cuanto a la exploración de la relación con sus usuarios, y que en el período estudiado ya contaba con una página de su comunidad en forma paralela a los textos ofrecidos por la revista.

18 Publicado en diciembre de 2015 por Anfibia, el texto se constituye como el más leído en el período estudiado y está disponible en http://revistaanfibia.com/ensayo/fuiste-un-lujo/ 


\section{DISERTACIONES}

ESTUDIOS

Los desafios del periodismo narrativo

ISSN: 1856-9536

Doi: https://doi.org/10.12804/revistas.urosario.edu.co/disertaciones/a.8246

Volumen 14, Número 1 / Enero-junio 2021

Versión PDF para imprimir desde

http://revistas.urosario.edu.co/index.php/disertaciones

Una de ellas está dada por la necesidad del periodismo literario digital de diferenciarse de su contexto mediático, desafío que impone la misión de explorar posibilidades y de poner en valor. Sumamos a esto el lugar que se atribuye a la representación del lector en el marco de un proceso productivo erosionado por el entorno digital y las estrategias implementadas en los textos y en el diseño de las publicaciones para atraerlo/la. Trabajamos también al temario como el producto comunicacional y puente que articula el contexto, al medio y a sus lectores/ras representados/as. Finalmente, relevamos la acción concreta de los destinatarios en el ejemplo de los comentarios.

Desde una perspectiva sociodemográfica, los entrevistados y entrevistadas hablaron de sus lectores/as representados/das como jóvenes que leen en dispositivos móviles y que buscan medios de segunda lectura (en tiempos de noticias falsas y señuelos de información). Se dijo de ellos y ellas que están interesados e interesadas en tratamientos que clarifiquen posicionamientos en torno de los temas en agenda, pero también en otros tópicos que se traduzcan en historias bien contadas. Estos lectores y lectoras tienen intereses tan específicos como diversos, se mueven en comunidades de redes sociales en virtud de tales propósitos y afinidades, y se comprometen con temas de denuncia relacionados con la impunidad del poder, libertades individuales, diversidades y derechos ciudadanos.

A esto se suma que en la práctica los destinatarios comentan 2 textos de cada 10, pero cuando lo hacen, exponen sus intenciones e intereses de manera bastante clara. Mediante una tipología de elaboración propia se clasificaron dichas intervenciones, y se determinó que la motivación principal en cada caso tuvo que ver con un alto grado de valoración positiva en general (tanto para la revista como para el tema y el tratamiento dado por el periodista), como también con identificación personal y emotiva (lo que se asocia al contenido local especialmente y al contenido político-ideológico). En el caso del texto más leído y comentado del período -a través del análisis y tomando las precauciones del caso-,$^{19}$ descubrimos que se trató de un ensayo escrito a modo de correspondencia personal, que apeló a la emotividad y a un posicionamiento ideológico ante un hecho histórico como lo fue el fin de la segunda presidencia de Cristina Fernández de Kirchner.

Por otra parte, desde los medios estudiados se emplearon recursos de escritura tradicionales (de la crónica y del nuevo periodismo) además de otros que fueron producto del aprendizaje colectivo en la web, aunque de forma combinada con estrategias de promoción y difusión de las marcas periodísticas, tales como la publicación de anuarios, realización de talleres y la gestión de eventos culturales.

El género narrativo habilitó una vez más nuevas mutaciones: textos más ensayísticos, investigativos, de distinta extensión, con mayor uso de fuentes y de voces, elaborados desde redacciones versátiles que se hicieron preguntas sobre las posibilidades de exploración de otros formatos y lenguajes. El temario resultante fue diverso y se ocupó de historias relacionadas con la agenda generalista u omitidas por ella, ofreciendo así mismo informes de investigación con rigor periodístico.

19 Solo se tuvieron en cuenta en este estudio los comentarios y conversaciones que se suscitaron en las páginas de las revistas, al pie de los textos (en tanto ámbitos más posibles de ser controlados o gestionados) y no los que aparecen en redes sociales. Esta investigación tampoco se ocupó de los intercambios que se producen en entornos sociales más privados, como WhatsApp, que tienen cada vez mayor importancia como plataformas de distribución y de comentarios sobre las noticias, y que están siendo utilizados por otro tipo de medios. 


\section{DISERTACIONES}

ESTUDIOS

Los desafíos del periodismo narrativo

ISSN: 1856-9536

Doi: https://doi.org/10.12804/revistas.urosario.edu.co/disertaciones/a.8246

Volumen 14, Número 1 / Enero-junio 2021

Versión PDF para imprimir desde

http://revistas.urosario.edu.co/index.php/disertaciones

En lo que hizo a los equipos de trabajo, los cambios que atraviesa la práctica periodística también alcanzaron a los emprendimientos estudiados. Los editores cumplen con múltiples roles, que van desde la búsqueda de colaboraciones a la planificación y corrección colaborativa de contenidos, sumando en muchos casos la venta de publicidad, la organización de eventos, publicación de anuarios, gestión en redes sociales y dictado de talleres. Encabezan así una mesa chica de trabajo, alrededor de la que giran otras partes fundamentales de la organización periodística: los colaboradores - quienes pueden ser más y menos asiduos-, como también diseñadores, reporteros gráficos e ilustradores. El pago de las colaboraciones o de los viáticos podía producirse o no, según el acuerdo colectivo al que se llegara y al momento económico que se atravesara.

Producto de esta investigación que se circunscribe al período 2012-2016 podemos decir también que las revistas de periodismo literario no estuvieron exentas en un cuadro de situación crítico para todas las producciones culturales en Argentina. La falta de políticas claras de apoyo al sector y las dificultades económicas del período que se agudizaron en diciembre de 2015 y que continuarían con la degradación del Ministerio de Cultura al rango de secretaría favorecieron la suspensión de las actualizaciones de al menos 5 del total de 9 revistas analizadas. ${ }^{20}$

Si bien este artículo no trabajó - por cuestiones de espacio- las circunstancias políticas y comunicacionales que se dieron sobre el final del período estudiado, lo cierto es que elementos estructurales incidieron en la crítica situación de medios de comunicación y en especial de los autogestionados, afectando a la libertad de expresión, a la democracia y, por ende, a la población en su conjunto.

En suma, aunque circunscribimos esta investigación a la instancia de producción y sus mensajes, sabemos que el destinatario del periodismo literario no asume ya un contrato de lectura exclusivo con cierto tipo de medios, sino que tiene una actitud selectiva en el contexto de una oferta informativa mayor a la que accede desde múltiples plataformas. Esto nos hace pensar en la potencialidad de estas revistas, que por sus modos organizativos pueden tomar decisiones en pos del conocimiento de estos destinatarios/as e implementar nuevas estrategias. Finalmente, a pesar de las condiciones contextuales críticas por las que se atravesó en los años sucesivos, estos medios demuestran que un periodismo de mejor calidad y comprometido con su tiempo es posible.

\section{Referencias}

1. Amado, A. (2018). El periodismo a diario: modelos profesionales en la prensa gráfica argentina. En ¿Qué periodismo se hace en Argentina? Perspectivas locales y globales. Konrad-Adenauer-Stiftung.

2. Bernardi, M. T. (2016). Transmedialidad y rutinas en medios digitales hiperlocales. En A. Rost, F. Bergero \& M. T. Bernardi (Eds.), Periodismo transmedia. La narración distribuida de la noticia (pp. 71-96). Universidad Nacional del Comahue (unco).

20 Del total de 9 revistas trabajadas, 5 dejaron de publicar, y si bien cuatro lo anunciaron públicamente a sus seguidores en redes sociales, una de ellas quedó en suspenso y había vuelto a hacerlo después de un año en silencio (Telaraña Digital, publicación del norte argentino), aunque al momento de escritura de este artículo ya no era posible verificar su continuidad. 


\section{DISERTACIONES}

3. Charmaz, K. (2013). La teoría fundamentada en el siglo xxl: aplicaciones para promover estudios sobre la justicia social. En N. K. Denzin \& Y. S. Lincoln (Comps.), Estrategias de investigación cualitativa. Vol. III (pp. 270-325). Gedisa.

4. Chillón, A. (1999). Literatura y periodismo: una tradición de relaciones promiscuas (1ª ed.). Universidad Autónoma de Barcelona.

5. Chillón, A. (2014). La palabra facticia: literatura, periodismo y comunicación (1ª ed.). Universidad Autónoma de Barcelona.

6. Defensoría del Público de Servicios de Comunicación Audiovisual. (2018). Informe 5 años de monitoreo. ¿Qué es noticia para los noticieros de televisión abierta? (febrero 2013-diciembre 2017). Dirección de Análisis, Investigación y Monitoreo. http://defensadelpublico.gob.ar/ analisis-de-cinco-anos-de-monitoreos-de-programas-noticiosos-de-canales-de-caba/

7. Fontcuberta, M., \& Borrat, H. (2006). Periódicos: sistemas complejos, narradores en interacción. La Crujía.

8. Herrscher, R. (2016). Periodismo narrativo: cómo contar la realidad con las armas de la literatura. Marea Editorial.

9. Larrondo Ureta, A. (2010). Propuesta metodológica para una aproximación empírica a los géneros ciberperiodísticos. zer: Revista de Estudios de Comunicación, 15(28), 157-174.

10. Luchessi, L. (2013). Calidad informativa: escenarios de postcrisis. La Crujía.

11. Montes, A. (2013). Políticas y estéticas de representación de la experiencia urbana en la crónica contemporánea. Corregidor.

12. Papalini, V. (2011). Literatura masiva, las marcas de la mundialización en las culturas nacionales. Análisis. Cuadernos de Comunicación y Cultura, (43), 73-87.

13. Pellegrini, S., Puente, S., Porath, W., \& Mujica, C. (2011). Valor agregado periodístico: la apuesta por la calidad de las noticias. Editorial de la Pontificia Universidad Católica de Chile.

14. Rincón, O. (2013). El periodista DJ es el medio. En Luchessi, L. (Ed.), Calidad informativa. Escenarios de poscrisis. La Crujía.

15. Rost, A. (2004). La actualidad múltiple en el periódico digital. Sala de Prensa, año VI, 3(69).

16. Zunino, E. (2018). Medios digitales: ¿quién tiene la palabra? Letra P. https://www.letrap.com.ar/ nota/2018-10-25-18-53-0-medios-digitales-quien-tiene-la-palabra 